\title{
APPLICATION OF HYDROACCUMULATION IN SYSTEM OF SOLAR POWER AND WATER SUPPLY FOR AUTONOMOUS CONSUMERS IN CONDITIONS OF MEXICO.
}

\author{
Cortez Liliana ${ }^{1}$, Cortez Jose Italo ${ }^{2}$, Perez Aguirre Jose Martín Carlos ${ }^{1}$, Bravo García Y. Elinor ${ }^{1}$, \\ Ramírez Popo Jesús A. ${ }^{3}$ \\ ${ }^{1}$ Facultad de Ciencias de la Electronica, ${ }^{2}$ Laboratorio de Metodos no Invasivos, ${ }^{3}$ Comisión \\ Federal de Electricidad \\ Universidad Autónoma de Puebla \\ México \\ e-mail:1cortez@ece.buap.mx, jitalo@siu.buap
}

Key words: photovoltaic system, solar radiation, hydroaccumulation, reversible regime

The analysis of the development of renewable sources in Mexico demonstrates that the country has a great potential for renewable resources, which are partially being used. Particularly, it is considered, that $3 / 4$ part of the territory receives in average 5 $\mathrm{kW} / \mathrm{m}^{2}$ to the day of the solar energy. As shown in figure 1 is the solar arrival of radiation for three climatic zones different in data base of observation.

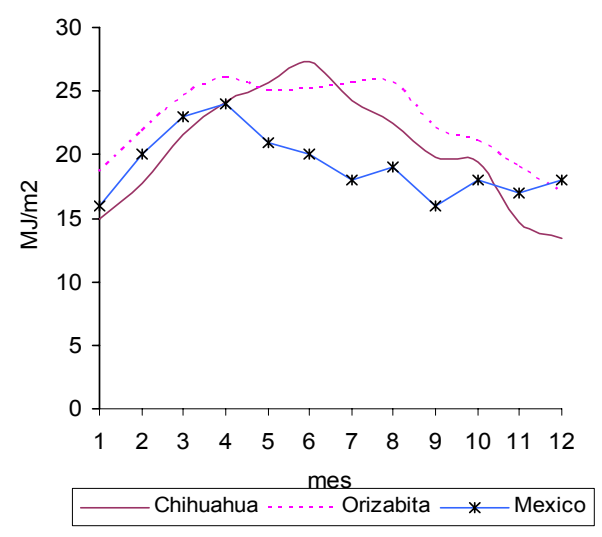

Fig. 1 Monthly average of the solar arrival of energy.

In Mexico, 20\% of the population, mainly in rural zones, has no stable supply of electrical energy, which represents a deficit of 36 TWh per year. The abundance of solar energy in Mexico on one hand, and on the other, the deficit of the energy supply with constant cost increases, makes the problem of developing effective and profitable systems for autonomous consumption of electrical energy, especially at present.

As a result of the development of a methodology to create the foundation for the parameters and structure of an autonomous solar system of energy supply, as well as potable water supply [1]; it was established that the water supply system used in Mexico offers a possibility of accumulating electrical energy, not only in a battery, but also in the form of potential water energy, which is pumped toward the upper tank of the house or building (Fig. 2). Traditionally, for a typical house, the water supply system is planned in such a way that the potable water is supplied in a centralized manner to a lower deposit of 10 to $30 \mathrm{~m}^{3}$ which is located in the basement of the house. For its daily use, in each house there is a pump which transports potable water necessary through pipes to the upper stationary tank, which is on the roof, whose volume is limited. Depending on the household's needs, water is supplied through the force of gravity.

This study of concordance between production and consumption process, of electrical energy as well as water supply, lead to the categorization of types of autonomous consumers, according to the graph of consumption, the house construction area and installed potency demand. 


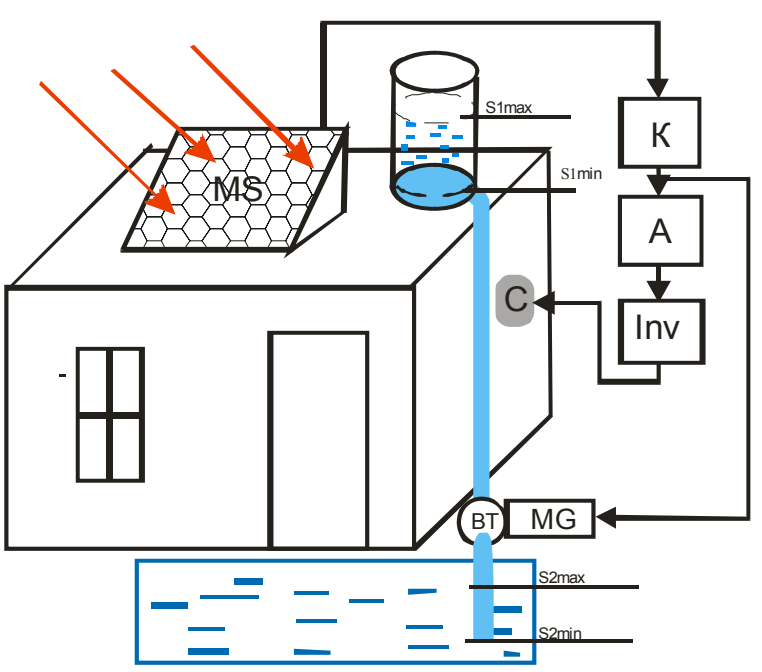

Fig.2 Typical structure of a photovoltaic system with hydroaccumulation.

For the accumulation of electrical energy and its later use, the use of the pump is possible, in the turbine regime and welling as the pumping regime; that is, the use of reversible hydraulic machinery. To raise water to a height of $25 \mathrm{~m}$, reversible encapsulated aggregates as well as centrifuge pumps and those with rotating blades have been used.

In the hydraulic and hydrodynamic studies made on the work [2], they confirm that the use of the pumps in turbine regime in practice does not require the special additional measures of reinforcement of the construction and of the elements of the liquid flow circuit.

The distinctive characteristic of the use of hydroaccumulation of electrical energy for supply of the same and supplying potable water to the user consists of that the pump works in the reversible regime and not only pumps water necessary for consumption, but also a water reserve is created, if needed, to assure the pump working in turbine regime. In this case, the motor impellor works in the generation regimen of electrical energy, which during heavy use in the afternoons and evenings may be incorporated into the system through the inverter, as shown in Figure 3. It is assumed that the upper tank allows the accumulation of water for domestic consumption and to generate electrical energy.

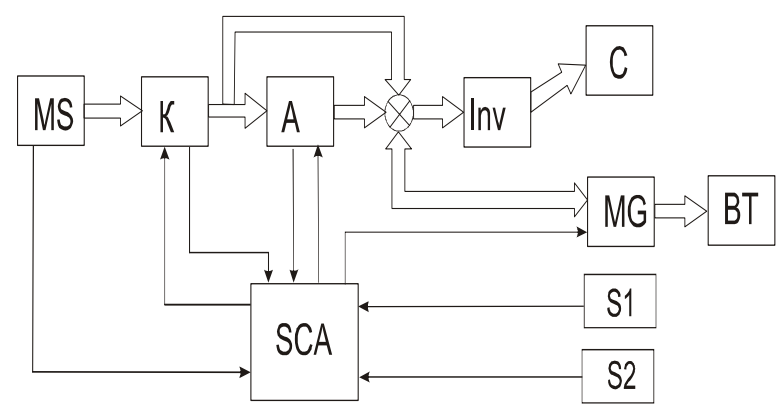

Fig.3 Configuration of the electrical energy and water supply system with hydroaccumulation.

Where: MS-solar module, K-controller; Abattery, Inv- inverter; C-consumer; S1,S2upper and lower reserve water level sensors; MG- generator engine; BT-turbine pump; SCA-automatic control system.

For determination of the optimal parameters of the MS, the distribution of consumption energy flows is carried out according to its characteristics and the time used (Figure 4).

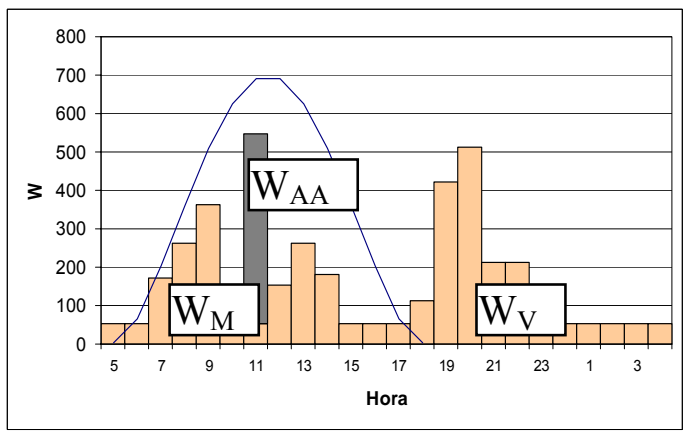

Fig.4 Graph of daily consumption.

The morning energy flow, which is used during daylight $W_{M}$, as well as, energy of the pump for water supply $W_{A A}$, pass through the inverter and controller, which causes the installed potency of the MS to increase in factor $\eta_{I n v} \cdot \eta_{K}$. The evening demand for energy supply demands that the increase be $\eta_{\text {Inv }} \cdot \eta_{K} \cdot \eta_{A}$

The values of the installed potency of the MS are determined with several parities between energies that pass through the battery $(\mathrm{A})$ and the hydroaccumulation system (HA). With this purpose, the coefficient $\mathrm{K}_{\mathrm{A}}$ is introduced as a variable component, representing the part of energy consumed by the afternoon and evening load $\left(\mathrm{W}_{\mathrm{v}}\right)$ of $\mathrm{A}$, see Figure 5 . 
Thus, the part of the energy that comes from $\mathrm{HA}$ is represented as $\left(\mathrm{K}_{\mathrm{A}}-1\right)$.

The introduction of this coefficient allows analysis of all the variety of the possible operation modes of this diagram. Of course, hydroaccumulation $\left(\mathrm{K}_{\mathrm{A}}=1\right)$ is not used up until the worst case scenario, when all the $\mathrm{W}_{\mathrm{v}}$ load is totally covered through HA $\left(\mathrm{K}_{\mathrm{A}}=0\right)$.
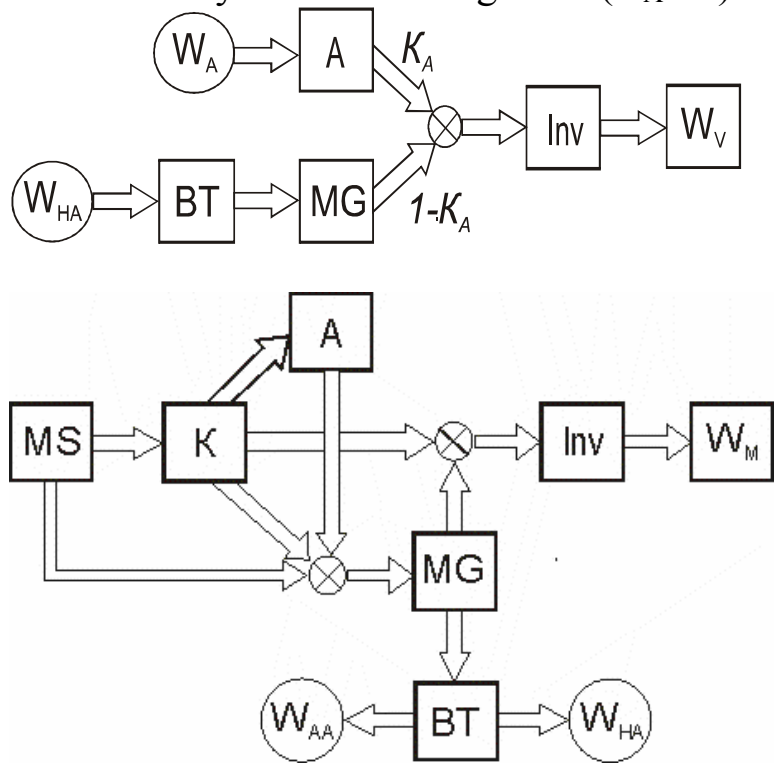

Fig.5 Energy flows of afternoon consumption $\mathrm{W}_{\mathrm{V}}$ and morning consumption $\mathrm{W}_{\mathrm{M}}$.

The installed potency o the MS is determined regarding the relationship between the energy accumulated in A and reserved in the HA system with the condition that the afternoon load is completely covered by $\mathrm{W}_{\mathrm{v}}=$ const. Finally the criterial equation would be:

$$
\begin{gathered}
K_{I} \cdot K_{2} \cdot \tau \cdot P h a \geq \\
\frac{W_{M}\left[\left(1-K_{A}\right) \eta_{b} \cdot \eta_{t u r b}+K_{A} \cdot \eta_{A}\right]}{\eta_{K}\left[\left(1-K_{A}\right) \eta_{b} \cdot \eta_{t u r b}+K_{A} \cdot \eta_{A}\right] \eta_{I n v}}+ \\
\frac{W_{V}+W_{A A}\left[\left(1-K_{A}\right) \eta_{b} \cdot \eta_{\text {turb }}+K_{A} \cdot \eta_{A}\right] \eta_{I n v}}{\eta_{K}\left[\left(1-K_{A}\right) \eta_{b} \cdot \eta_{\text {turb }}+K_{A} \eta_{A}\right] \eta_{I n v}}
\end{gathered}
$$

where $\mathrm{K}_{1}$ - coefficient of reduction in MS production in morning and afternoon hours; $\mathrm{K}_{2}$-coefficient of reduction of MS production due to contamination and cloudiness of the atmosphere; $\tau$ - duration of the day; $\mathrm{W}_{\mathrm{M}}, \mathrm{W}_{\mathrm{V}}$ - consumption of morning and afternoon energy; $\mathrm{W}_{\mathrm{AA}}$ - energy consumed by the water supply system; $\eta_{\text {Inv }} ; \eta_{\mathrm{K}} ; \eta_{\mathrm{A}}-$ efficacy of the Inv, $\mathrm{K}$ and $\mathrm{A}$ respectively; $\eta_{\mathrm{b}} ; \eta_{\text {turb }}-$ efficacy of the electrical motor in the pump and turbine mode.

The later studies carried out in a typical house with area of construction of $50 \mathrm{~m}^{2}$ and a daily total consumption of the electrical energy of $\mathrm{W}=3600 \mathrm{Wh}$ and use of around 2 $\mathrm{m}^{3}$ of water. In this case, it was established that the power of the MS is approximately $1000 \mathrm{~W}$, the capacity of the A is close to 100 $\mathrm{Ah}$, the inverter power $600-800 \mathrm{~W}$ and the horsepower of the pump is approximately $600 \mathrm{~W}$.

Finally it is certain the capacity of the Qa battery storage and relative growth of installed power $\mathrm{P}_{\mathrm{HA}}$ for different values from $K_{A}$, using the criterial equation (fig.6).

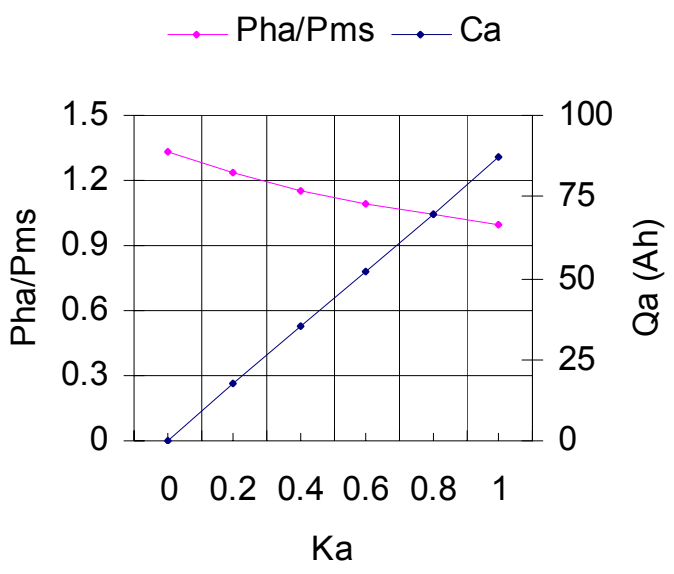

Fig.6 Graph of changes of the parameters in function of degree hydroaccumulation.

The graph it's shown two contradictory tendencies, on the one hand, increasing the level of HA, the installed power should be increased, but at the same time diminishes the necessary capacity of the battery storage. It's showed that the HA is recommended for partial use for the levels of HA in interval $0.85 \leq \mathrm{K}_{\mathrm{A}} \leq 1$. In this case, the character of the graph of consumption is smoothed out, allowing improving the efficiency of the battery storage and at the same time to diminish its capacity.

To guarantee the optimal conditions of exploitation, an algorhythm was created to the automatic control system, which is shown in Figure 7, which includes the solar radiation resource determination models, diagnosis of the state of the battery, the condition of maximum potency transfer of 
the MS, as well as the control of the pump installation.

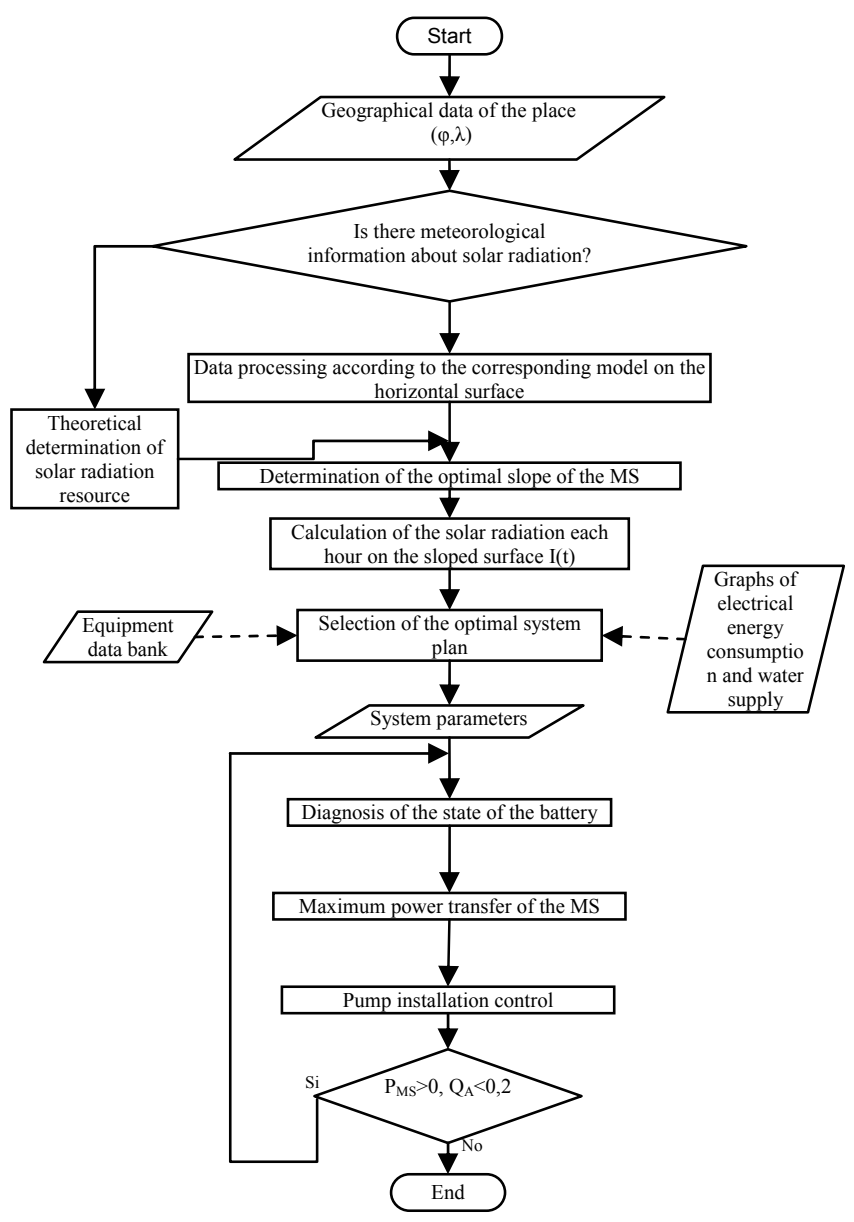

Fig.7 ACS Algorhythm

Said algorhythm simultaneously solves problems related to the battery load level, optimization of power transfer to the consumer and to the battery, as well as determination of the pump installation work regarding the availability of power from the MS and the demand of consumption.

Conclusions

High level of intensity of a solar energy (14$26 \mathrm{MJ} / \mathrm{m} 2$ ) predetermines an opportunity of creation of effective and profitable photovoltaic systems. For conditions of Mexico the integrated decision of the requirement of the electric power and water supply is essential provision for decentralized consumer of low power. Using existing infrastructure the system supply it is offered to use it for application of hydroaccumulation.

In a consequence, research leads to a substantiation of the criterial equation which allows defining the installed power, depending on a degree of hydroaccumulation The analysis, carried out for several values of energy consumption, showed that the HA is recommended for partial use, in this case the work regime graph of the $\mathrm{A}$ in afternoon hours is smoothed out, allowing its capacity to decrease substantially and the efficacy of the battery to increase, lengthening its life. The algorhythm to the automatic control system, guarantees optimal conditions of operation of the system

\section{References:}

[1] Cortez Liliana. Estimación de los parámetros de un sistema solar de abastecimiento de energía eléctrica para consumidores individuales (en condiciones de México). Tesis Doctoral. SPbGPU, San Peterburgo, Rusia. 2004.

[2] Elistratov V.V. Acumulación de energía de las fuentes renovables. Moscú, Amipress, 2002.

[3] B.H. Chowdhury Saifur Rahman Analysis of interrelationships between photovoltaic power and battery storage for electric utility load management. Electrical Engineering Department, Virginia Tech Blacksburg. VA 24061, USA; IEEE Transactions on Power Systems, Vol. 3, No. 3, August 1988

[4] Elistratov V. V., Kuznetsov M.V. Fundamentos teóricos de la energética no-tradicional y renovable. (en ruso), SPbGPU, S.-Peterburgo, Rusia 2004. 